\title{
Anne Douaire, Contrechamps tragiques
}

\section{Paola Ghinelli}

\section{(Q) OpenEdition}

\section{Journals}

\section{Édition électronique}

URL : http://journals.openedition.org/studifrancesi/30912

DOI : 10.4000/studifrancesi.30912

ISSN : 2427-5856

\section{Éditeur}

Rosenberg \& Sellier

\section{Édition imprimée}

Date de publication : 1 avril 2006

Pagination : 202

ISSN : 0039-2944

\section{Référence électronique}

Paola Ghinelli, « Anne Douaire, Contrechamps tragiques », Studi Francesi [En ligne], 148 (XLX | I) | 2006,

mis en ligne le 30 novembre 2015, consulté le 18 avril 2021. URL : http://journals.openedition.org/ studifrancesi/30912 ; DOI : https://doi.org/10.4000/studifrancesi.30912

\section{Ce document a été généré automatiquement le 18 avril 2021.}

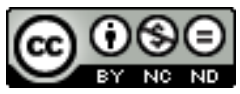

Studi Francesi è distribuita con Licenza Creative Commons Attribuzione - Non commerciale - Non opere derivate 4.0 Internazionale. 


\title{
Anne Douaire, Contrechamps tragiques
}

\author{
Paola Ghinelli
}

\section{RÉFÉRENCE}

ANNE DOUAIRE, Contrechamps tragiques, Paris, Presses de l'Université Paris Sorbonne, 2005

(«Lettres Francophones»), pp. 372.

1 La collection «Lettres Francophones» dirigée par Beïda Chikhi débute avec un ouvrage dense et novateur. Dans Contrechamps tragiques, Anne Douaire propose un parcours dans la littérature antillaise de la deuxième moitié $\mathrm{du} \mathrm{XX}^{\mathrm{e}}$ siècle dont le but principal est l'étude du concept de tragique. En particulier, l'auteur s'interroge sur les formes que peut prendre le tragique, strictement lié au «sens commun» et aux valeurs partagées, dans un contexte colonial et postcolonial. Cet aspect du canon est-il réinterprété ou refusé dans la littérature antillaise contemporaine?

2 La tentative de réponse à cette question est une véritable déconstruction du tragique en tant que genre. D'un côté l'interprétation littéraire antillaise de cette notion est subtilement analysée, de l'autre l'auteur essaie de redéfinir le tragique contemporain par le biais de son volet caraibe. Il s'agit là d'une révolution importante, car si la littérature antillaise a été souvent considérée par rapport à la notion de désastre et à celle d'identité, les critiques se sont rarement interrogés sur son rapport avec le canon. Anne Douaire montre que la comparaison est possible sans pour autant lire son corpus de manière unilatérale. Le champ littéraire contemporain incorpore le champ antillais, car chaque œuvre est en relation avec les autres. En particulier, la littérature antillaise exprimerait l'irrémédiable par un renversement entre le passé et le dénouement. La tension tragique antillaise entre la durée et le figement d'un côté et la fulgurance extratemporelle de l'autre est ainsi interprétée par Douaire comme un exemple du nouveau tragique qui se réfugie dans l'instant. L'auteur parle d'un tragique de la 
latence, et elle fait clairement allusion aux conséquences novatrices que cette notion et d'autres qu'elle propose peuvent avoir si elles sont appliquées à la littérature mondiale.

3 Cet essai conjuguant une certaine originalité à une argumentation serrée est la réélaboration de la thèse de doctorat de son auteur. Le corpus qui, nous reprenons ici les propos d'Anne Douaire, «est large et non justifié», permet de sortir des voies tracées par la critique précédente. Il inclut un grand nombre d'auteurs, d'Aimé Césaire à Édouard Glissant, de Simone Schwarz-Bart à Daniel Maximin, ce qui rend l'ouvrage incontournable pour tous les spécialistes. En même temps, la rigueur de ses démonstrations et la remise en cause du canon qu'il propose en font un point de repère pour tous ceux qui s'intéressent à la littérature de langue française et non. 